\title{
Effectiveness of first trimester ultrasound screening in reduction of postdated labor induction rate
}

\author{
Saugat Koirala ${ }^{1 *}$, Achala Thakur ${ }^{2}$, Rubina Rai' ${ }^{2}$, \\ Baburam Dixit Thapa ${ }^{2}$, Ashok Raj Pant ${ }^{3}$
}

\begin{abstract}
${ }^{1}$ Department of Obstetrics and Gynecology, Haamro Sahayatri Hospital, Kathmandu, Nepal
${ }^{2}$ Department of Obstetrics and Gynecology, ${ }^{3}$ Department of Radiodiagnosis, BP Koirala Institute of Health Sciences (BPKIHS), Dharan, Nepal
\end{abstract}

Received: 16 August 2021

Revised: 30 August 2021

Accepted: 31 August 2021

\author{
*Correspondence: \\ Dr. Saugat Koirala, \\ E-mail: saugatkoirala.sk@gmail.com
}

Copyright: (c) the author(s), publisher and licensee Medip Academy. This is an open-access article distributed under the terms of the Creative Commons Attribution Non-Commercial License, which permits unrestricted non-commercial use, distribution, and reproduction in any medium, provided the original work is properly cited.

\begin{abstract}
Background: The gestational age calculation by ultrasonography (USG) at first trimester is based on crown-rump length is more accurate, less erratic than last menstrual period based dating. Utilization of first trimester based scanning in dating the pregnancy will reduce the labor induction rate and consequently reduce the morbidity related to induction of labor.

Methods: A comparative cross-sectional study was done among 314 booked antenatal women visiting department of obstetrics and gynecology, BPKIHS for regular check-up between 37 and 41 weeks of gestation. Expected date of delivery was calculated from crown rump length (CRL) of the first trimester scan for USG group while last menstrual period was taken to calculate expected date of delivery for LMP group and were called for induction at 41 weeks of gestation. The rates of labor induction, emergency cesarean section (CS) among induced group, indication of CS and mode of delivery were compared in both the groups.

Results: There was 14\% labor induction rate in USG group and 24.2\% in LMP (last menstrual period) group and differed significantly $(\mathrm{p}=0.022)$. There was no difference in the mode of delivery among participants in either groups. The rate of emergency CS among women undergoing induction of labor was $54.5 \%$ and $39.5 \%$ respectively for USG and LMP groups $(\mathrm{p}=0.258)$. Overall, non-reassuring fetal heart rate was the most common indication for CS in both the groups.

Conclusions: The finding suggests first trimester scan among all pregnancies will reduce the post-dated inductions, as well as need of CS.
\end{abstract}

Keywords: Antenatal women, First trimester dating scan, Postdated pregnancy, Induction of labor

\section{INTRODUCTION}

Induction of labor remains one of the most routinely performed procedure in obstetrics with induction rates varying from $6.8 \%$ to $33 \%$ in Europe, $24.5 \%$ in the United States and $35.5 \%$ in Sri Lanka. ${ }^{1}$ This procedure artificially ripens the cervix and starts uterine contraction in those who are not in labor leading to dilatation of their cervix and ends in vaginal birth of the baby. ${ }^{2}$ There are various fetal and or maternal conditions for which induction of labor is indicated like abruptio placenta, chorioamnionitis, fetal demise, gestational hypertension, preeclampsia, eclampsia, premature rupture of membranes, post-term pregnancy, maternal medical conditions (diabetes mellitus, renal disease, chronic pulmonary disease, chronic hypertension, antiphospholipid syndrome) or fetal compromise (severe fetal growth restriction, isoimmunization, oligohydramnios). ${ }^{3}$ 
In 2011, the incidence of post-term pregnancy was $5.5 \%$ in the United States, the incidence of CS among those who had 41 completed weeks of gestation was $30.5 \%$ and those who had completed 42 weeks of pregnancy was $28.5 \% .^{4}$ Post-term pregnancy is a term to define a pregnancy which has reached or crossed past 42 weeks of gestation from the LMP, while late-term pregnancy is a term given for a pregnancy that has reached between 40 completed weeks and 41 weeks and 6 days of gestation. ${ }^{5}$ Elective induction of labor at or following 41 weeks of gestation decreases perinatal morbidity and mortality of postdated pregnancy. ${ }^{6}$ WHO recommends induction of labor in women who have reached 41 weeks of pregnancy. ${ }^{7}$ Dating of pregnancy can be done by both USG or first day of LMP and among them first trimester USG is more valuable to estimate the gestational age. ${ }^{8}$ First-trimester crown-rump length for the determination of period of gestation has been recommended by guidelines as the best parameter to reduce the induction of labor for post-term pregnancies. ${ }^{9-}$ 11 A study by Treger et al concluded that in order to decrease the rate of $\mathrm{CS}$, meconium-stained liquor, macrosomic baby, induction of labor should be considered before 42 weeks. ${ }^{12}$ The use of routine first trimester dating ultrasound has lowered the overall rate of post-term pregnancy. ${ }^{13}$ Misoprostol, in oral or vaginal form, is a potent agent for induction of labor and results in fewer CS compared to oxytocin or vaginal dinoprostone. ${ }^{14}$ American college of obstetrics and gynecology (ACOG) recommends consideration of a dose of $25 \mathrm{mcg}$ of misoprostol in approximation for induction of labor in a frequency of no more than 3-6 hours. ${ }^{3}$

In low middle income countries like Nepal, the number of antenatal check-up (ANC) visits by pregnant women are limited, with most of them visiting the clinics only by second trimester. ${ }^{15}$ Utilization of obstetric ultrasonographic scan in rural areas of Nepal is very low, with only one-fourth of them receiving the procedure in their most recent pregnancy. ${ }^{16}$ This study was focused on assessing the significance of first trimester ultrasound to reduce the induction rate for postdated pregnancy. The primary objective of our study was to compare rate of induction of labor among groups with or without first trimester ultrasound scan. The secondary objectives were to study mode of delivery among both the groups and need of CS among induced postdated pregnancy.

\section{METHODS}

This was a prospective comparative hospital study done from 3 April 2017 to 2 April 2018. All booked pregnant women presenting to department of obstetrics and gynecology, BPKIHS, Dharan, Nepal and who gave consent to participate in the study after were considered for the study if they met the criteria for enrolment in this study.

\section{Inclusion criteria}

Singleton pregnancy in cephalic presentation; no contraindications for normal vaginal delivery and USG performed for 1 st trimester dating scan done by certified radiologist in one group and USG not performed for $1 \mathrm{st}$ trimester dating scan in another group were included in the study.

\section{Exclusion criteria}

Patients with multiple gestation; gestational diabetes mellitus or overt diabetes mellitus; hypertensive disorders of pregnancy; irregular menstrual cycle; intrauterine growth restriction and intrauterine fetal death were excluded from the study.

The independent variable was calculation of expected date of delivery (EDD) by first trimester USG (USG group) or by first day of LMP (LMP group), while dependent variable was the rate of induction among both groups. Furthermore, the primary outcome of the study was rate of induction of labor among USG group and LMP group. The secondary outcomes were mode of delivery among both groups, rate of CS on induced patient on each group, indication of CS among each group.

Sample size was calculated with the formula,

$\mathrm{N}=\frac{\left(Z \alpha / 2+Z_{\beta}\right)^{2} \times p 1(1-p 1)+p 2(1-p 2)}{(p 1-p 2)^{2}}$,

where,

$\mathrm{p} 1=22 \%,{ }^{17}$

$\mathrm{p} 2=37 \%,{ }^{17}$

$\mathrm{Z}_{\alpha / 2}=1.96$,

$\mathrm{Z}_{\beta}=0.84$ at $80 \%$ power,

where,

$\mathrm{Z}_{\alpha / 2}$ is the critical value of the normal distribution at $\alpha / 2$,

$Z_{\beta}$ is the critical value of the normal distribution at $\beta$,

p1 and p2 are the expected sample proportions of the two groups,

hence, $\mathrm{N}=142$ in each group,

considering the loss to follow up of $10 \%$, the final samples size $(N)=157$ in each group.

Enrolment was done using convenient sampling from antenatal pregnant women visiting the department of obstetrics and gynecology, BPKIHS. The outcome variables were followed once the patient got admitted for delivery. The patients were divided into two groups USG group and LMP group. USG group consisted of women in whom EDD was calculated by CRL of the scan performed 
on the first trimester while LMP group consisted of women who had no USG done in first trimester and in whom EDD was calculated based on the first day of the last menstrual period. All the standard date for women on USG group was based on dating scan, CRL parameter of the first trimester while those on LMP group was based on first day of LMP. USG group were recruited after 37 completed weeks till 40 weeks and 6 days as calculated by dating scan, while LMP group was recruited in the same way but according to their LMP. Unless they progressed spontaneously into labor or they had any indication for emergency delivery, they were asked to follow up at 41 weeks of gestation by the dating scan or by first day of the last menstrual period based on the group they belonged. They were induced with $25 \mathrm{mcg}$ of misoprostol for the purpose of induction of labor given every 4 hourly for a maximum of 3 doses. When the situation warranted CS, it was done for any fetal or maternal indications. They were followed up in the antenatal ward or labor room at the time of delivery.

The study was started after receiving ethical approval (IRC/0863/016) from the institutional review committee (IRC), BPKIHS. Anonymity and confidentiality of all the participants was maintained. Informed consent was obtained from all the pregnant women. Only the researcher had access to the collected data and it was utilized only for the purpose of the research.

Data was entered in Microsoft excel 2016 and converted into statistical package for social sciences (SPSS 16) for statistical analysis. Frequency and percentage was used to present quantitative data. A level of significance was set at 5\%. Pearson's Chi square test was used for bivariate analysis between variables.

\section{RESULTS}

In both groups, more than half of the participants belonged to the age group of 15-24 years (Table 1). The mean age of participants in this study was $24.49 \pm 4.18$ years. Majority of the study participants were primigravida (Table 1).

The rate of induction of labor was $14 \%$ in USG group and $24.2 \%$ in LMP group ( $\mathrm{p}=0.022)$. Most of the women in both the groups had spontaneously progressed into labor accounting for 254 out of all the 314 participants in this study. Vaginal route was the mode of delivery in $84.7 \%$ of the women in USG group and $82.2 \%$ in LMP group $(\mathrm{p}=0.544)$ (Table 2). Induction of labor was performed in 60 patients among the 314 participants. Among the induced women, emergency CS was done on 12 out of 22 women among the USG group and 15 out of 38 women in LMP group (Table 3). Mode of delivery following induction of labor was normal vaginal delivery in $45.5 \%$ of the women in USG group and $60.5 \%$ in LMP group $(\mathrm{p}=0.258)$ (Table 3).
Table 1: Characteristics of participants in USG and LMP groups $(\mathrm{N}=157)$.

\begin{tabular}{|lll|}
\hline Categories & Groups \\
\hline Age (in years) & & \\
\hline $15-24$ & $83(52.9)$ & $84(53.5)$ \\
\hline $25-34$ & $72(45.9)$ & $70(44.6)$ \\
\hline 35 and above & $2(1.3)$ & $3(1.9)$ \\
\hline Total & $157(100.0)$ & $157(100.0)$ \\
\hline Gravidity & & \\
\hline Primigravida & $101(64.3)$ & $94(59.9)$ \\
\hline Multigravida & $56(35.7)$ & $63(40.1)$ \\
\hline Total & $157(100.0)$ & $157(100.0)$ \\
\hline
\end{tabular}

Table 2: Mode of onset of labor and delivery among USG and LMP groups (N=157).

\begin{tabular}{|c|c|c|c|}
\hline \multirow[b]{2}{*}{ Categories } & \multicolumn{2}{|l|}{ Groups } & \multirow[b]{2}{*}{$\begin{array}{l}\mathbf{P} \\
\text { value }\end{array}$} \\
\hline & $\begin{array}{l}\text { USG } \\
\text { group (\%) }\end{array}$ & $\begin{array}{l}\text { LMP } \\
\text { group (\%) }\end{array}$ & \\
\hline \multicolumn{4}{|c|}{ Mode for onset of labor } \\
\hline Induced & $22(14.0)$ & $38(24.2)$ & \multirow{3}{*}{0.022} \\
\hline Spontaneous & $135(86.0)$ & $119(75.8)$ & \\
\hline Total & $\begin{array}{l}157 \\
(100.0)\end{array}$ & $\begin{array}{l}157 \\
(100.0)\end{array}$ & \\
\hline \multicolumn{4}{|l|}{ Mode of delivery } \\
\hline $\begin{array}{l}\text { Normal vaginal } \\
\text { delivery }\end{array}$ & $133(84.7)$ & $129(82.2)$ & \multirow{3}{*}{0.544} \\
\hline $\begin{array}{l}\text { Emergency } \\
\text { cesarean section }\end{array}$ & $24(15.3)$ & $28(17.8)$ & \\
\hline Total & $\begin{array}{l}157 \\
(100.0)\end{array}$ & $\begin{array}{l}157 \\
(100.0)\end{array}$ & \\
\hline
\end{tabular}

Table 3: Mode of delivery among induced women $(\mathrm{N}=60)$.

\begin{tabular}{|c|c|c|c|c|}
\hline \multirow[t]{2}{*}{ Groups } & \multicolumn{2}{|c|}{$\begin{array}{l}\text { Mode of delivery } \\
\text { among induced } \\
\text { women }(\%)\end{array}$} & \multirow[t]{2}{*}{$\begin{array}{l}\text { Total } \\
(\%)\end{array}$} & \multirow[t]{2}{*}{$\begin{array}{l}\mathbf{P} \\
\text { valu } \\
\mathbf{e}\end{array}$} \\
\hline & NVD & Em. CS & & \\
\hline USG & $10(45.5)$ & $12(54.5)$ & $22(100)$ & \multirow{3}{*}{0.258} \\
\hline LMP & $23(60.5)$ & $15(39.5)$ & $38(100)$ & \\
\hline Total & $33(55.0)$ & $27(45.0)$ & $60(100)$ & \\
\hline
\end{tabular}

Table 4: Indications of emergency CS (N=52).

\begin{tabular}{|lll|}
\hline $\begin{array}{l}\text { Indication of em. } \\
\text { CS }\end{array}$ & $\begin{array}{l}\text { USG } \\
\text { group }(\%)\end{array}$ & $\begin{array}{l}\text { LMP group } \\
(\%)\end{array}$ \\
\hline $\begin{array}{l}\text { Non reassuring } \\
\text { fetal heart rate }\end{array}$ & $11(45.8)$ & $12(42.9)$ \\
\hline $\begin{array}{l}\text { Failed induction of } \\
\text { labor }\end{array}$ & $8(33.3)$ & $10(35.7)$ \\
\hline $\begin{array}{l}\text { Meconium stained } \\
\text { liquor }\end{array}$ & $2(8.3)$ & $2(7.1)$ \\
\hline Others & $3(12.5)$ & $4(14.3)$ \\
\hline Total & $24(100)$ & $28(100)$ \\
\hline
\end{tabular}


Out of the 314 participants, 52 women had undergone emergency CS (em. CS) for various obstetric indications. The major indications for emergency CS among all participants in both the groups were non reassuring fetal heart rate followed by failed induction of labor, meconium stained liquor and others (Table 4).

\section{DISCUSSION}

Use of CRL of first trimester USG has been shown to have more accuracy and less errors in calculation of EDD. ${ }^{18} \mathrm{We}$ had considered this parameter to be used to calculate the EDD in women for the purpose of lowering the labor induction in one group. Another group were women whose calculation of EDD was done with first day of the LMP. In a study by Bennet et al labor induction rate was found to be $4.8 \%$ when use of first trimester scan was used for dating as compared to $13 \%$ when second trimester was used as a dating scan. ${ }^{19}$ Similar to that study, our study showed significant low labor induction rate with first trimester USG. The LMP group had $24.2 \%$ induction rate while the USG group had 14\% induction rate. However, our comparison group were LMP group as compared to second trimester scan group used in the study by Bennet et al. ${ }^{19}$ Our results were contradictory to that of two other studies which had concluded that there was no change in labor induction rate for prolonged pregnancy between the group with scan or no scan group. ${ }^{20,21}$

Our study showed no significance among the cesarean rate among the women undergoing induction of labor in both the groups. This was similar to the findings in other two studies. ${ }^{19,20}$ Furthermore, a randomized controlled trial which compared induction of labor versus expectant management for pregnancy of 41 weeks onwards till 42 weeks and 6 days, had suggested that induction of labor has higher rate of CS as compared to expectantly managed groups. $^{22}$ In that study that rate of CS was significantly higher in women undergoing induction of labor. ${ }^{22}$ Another study had also found more than two times increase in the chances of CS among women where use of labor induction was done as compared to spontaneous onset of labor. ${ }^{23}$

In our study, the incidence of CS among the women induced in either USG or LMP group were $54.5 \%$ and $39.5 \%$ respectively. This rate of CS was higher as compared to a COHORT study of around 19 million pregnant women in which 19.2 percent of women had underwent $\mathrm{CS}$ after the labor induction process. ${ }^{24}$ This might be attributed to a large sample size in that study compared to our study and also inclusion of cases (e.g. intra uterine fetal death) considered which had favored progress of labor vaginally. ${ }^{24}$

To avoid the various indications and related morbidities related with $\mathrm{CS}$, first trimester dating scan offered a relative reduction in the labor induction rate. Therefore, it would be a good rational for a routine practice of first trimester scan and its application in calculating the EDD based on this parameter.

\section{Limitation}

The main limitation of our study was that the maternal complications associated with induction of labor apart from CS (for example uterine rupture, postpartum hemorrhage) was not studied.

\section{CONCLUSION}

First trimester USG using CRL parameter is more effective as a dating scan for the purpose of reduction of induction of labor in comparison to LMP based dating. The rate of induction is significantly reduced in women who use first trimester CRL for calculating EDD. Those women whose EDD was based on the first trimester CRL based scan were more likely to undergo spontaneous vaginal delivery. Induction of labor in all participants, irrespective of the method for the calculation of EDD, is a major risk factor for CS. Thus, a routine use of first trimester scan as a dating scan can avoid induction of labor and let woman undergo spontaneous progression of labor.

\section{ACKNOWLEDGMENTS}

We would like to thank our teachers especially Dr. Mohan Chandra Regmi who had constantly motivated me to pursue this research work. We would also like to thank Dr. Smriti Pant who gave me ideas in improvising the editing. Also, we would like to show my gratitude towards the participants who had shown faith in this study and given permission to carry out the study.

Funding: No funding sources Conflict of interest: None declared

Ethical approval: The study was approved by the Institutional Ethics Committee

\section{REFERENCES}

1. Marconi AM. Recent advances in the induction of labor. F1000Res. 2019;8:1000.

2. Induction of labour. Evidence-based Clinical Guideline Number 9. Clinical Effectiveness Support Unit. London: Royal College of Obstetricians and Gynaecologists; 2001.

3. ACOG practice bulletin no. 107: induction of labor. Obstet Gynecol. 2009;114:386-97.

4. Martin JA, Hamilton BE, Osterman MJ, Curtin SC, Matthews TJ. Births: Final data for 2013. Natl Vital Stat Rep. 2015;64(1):1-65.

5. Spong CY. Defining "term" pregnancy: recommendations from the defining "term" pregnancy workgroup. JAMA. 2013;309(23):2445-6.

6. Hussain AA, Yakoob MY, Imdad A, Bhutta ZA. Elective induction for pregnancies at or beyond 41 weeks of gestation and its impact on stillbirths: a systematic review with meta-analysis. BMC Pub Health. 2011;11(3):5.

7. World Health Organization. WHO recommendations: induction of labour at or beyond term: World Health 
Organization; 2018. Available at: https://apps. who.int/iris/bitstream/handle/10665/277233/9789241 550413-eng.pdf. Accessed on 3 June 2021.

8. Doubilet PM. Should a first trimester dating scan be routine for all pregnancies? Semin Perinatol. 2013;37(5):307-9.

9. Butt K, Lim KI. Guideline no. 388-determination of gestational age by ultrasound. J Obstet Gynaecol Can. 2019;41(10):1497-507.

10. Butt K, Lim K, Bly S, Cargill Y, Davies G, Denis N, et al. Determination of gestational age by ultrasound. J Obstetr Gynaecol Canada. 2014;36(2):171-81.

11. Ohuma EO, Papageorghiou AT, Villar J, Altman DG. Estimation of gestational age in early pregnancy from crown-rump length when gestational age range is truncated: the case study of the INTERGROWTH-21 st Project. BMC Med Res Methodol. 2013;13(1):151.

12. Treger M, Hallak M, Silberstein T, Friger M, Katz M, Mazor M. Post-term pregnancy: should induction of labor be considered before 42 weeks? J Mat Fetal Neonat Med. 2002;11(1):50-3.

13. Galal M, Symonds I, Murray H, Petraglia F, Smith R. Postterm pregnancy. Facts View Vision Obgyn. 2012;4(3):175.

14. Alfirevic Z, Weeks A. Oral misoprostol for induction of labour. Cochrane Database Syst Rev. 2006;2:001338.

15. Tuladhar H, Dhakal N. Impact of antenatal care on maternal and perinatal utcome: a study at Nepal medical college teaching hospital. Nepal J Obstetr Gynaecol. 2011;6(2):37-43.

16. Kozuki N, Katz J, Khatry SK, Tielsch JM, LeClerq SC, Mullany LC. Community survey on awareness and use of obstetric ultrasonography in rural Sarlahi District, Nepal. Int J Gynecol Obstetr. 2016;134(2):126-30.

17. Bennett K, Crane J, O’Shea P, Lacelle J, Hutchens D, Copel J. Combined first-and second-trimester ultrasound screening is effective in reducing postterm labor induction rates: a randomized, controlled trial. Ultrasound Med Biol. 2003;29(5):65.
18. Chalouhi G, Bernard J, Benoist G, Nasr B, Ville Y, Salomon LJ. A comparison of first trimester measurements for prediction of delivery date. J Mat Fetal Neonat Med. 2011;24(1):51-7.

19. Bennett KA, Crane JM, O'shea P, Lacelle J, Hutchens D, Copel JA. First trimester ultrasound screening is effective in reducing postterm labor induction rates: a randomized controlled trial. Am J Obstetr Gynecol. 2004;190(4):1077-81.

20. Harrington D, MacKenzie I, Thompson K, Fleminger $\mathrm{M}$, Greenwood C. Does a first trimester dating scan using crown rump length measurement reduce the rate of induction of labour for prolonged pregnancy? An uncompleted randomised controlled trial of 463 women. BJOG Int $\mathrm{J}$ Obstetr Gynaecol. 2006;113(2):171-6.

21. Ewigman BG, Crane JP, Frigoletto FD, LeFevre ML, Bain RP, McNellis D, et al. Effect of prenatal ultrasound screening on perinatal outcome. New England J Med. 1993;329(12):821-7.

22. Thangarajah F, Scheufen P, Kirn V, Mallmann P. Induction of labour in late and postterm pregnancies and its impact on maternal and neonatal outcome. Geburtshilfe und Frauenheilkunde. 2016;76(07):7938.

23. Ehrenthal DB, Jiang X, Strobino DM. Labor induction and the risk of a cesarean delivery among nulliparous women at term. Obstetr Gynecol. 2010;116(1):35-42.

24. Rossi RM, Requarth E, Warshak CR, Dufendach KR, Hall ES, DeFranco EA. Risk calculator to predict cesarean delivery among women undergoing induction of labor. Obstetr Gynecol. 2020;135(3):559-68.

Cite this article as: Koirala S, Thakur A, Rai R, Thapa BD, Pant AR. Effectiveness of first trimester ultrasound screening in reduction of postdated labor induction rate. Int J Reprod Contracept Obstet Gynecol 2021;10:3698-702. 